\title{
Chemopreventive compounds from plant derived food and their bioactivity
}

\author{
Ablassé Rouamba', Moussa Compaoré2, Martin Kiendrebeogo ${ }^{3}$ \\ ${ }^{1}$ Assistant, ${ }^{2}$ Assistant Professor, ${ }^{3}$ Professor and Head, Laboratory of Applied Biochemistry and Chemistry, University \\ Ouaga I Pr Joseph KY-ZERBO, 03 BP 7021 Ouagadougou 03, Burkina Faso
}

Terrestrial plants, especially higher plants, have a long history of use for the treatment of many human diseases such as ailment, cancer, diabetes, neurodegenerative and cardiovascular disorders. Since then, many studies have been designed to evaluate biochemical properties of whole plant extract, fractions or isolated compounds. Several researches have established the relation between consumption of plant derived products to minimize the oxidative stress and diseases associated with stress. These beneficial biological properties on animal health has been attributed to certain classes of metabolites contents in plants including anthocyanins, flavonols, tannins, carotenoids, terpenoids, alkaloids and vitamins. The bioactivity of these compounds is due to their ability to scavenge reactive oxygen species (ROS) or NOS or to modulate antioxidant enzymes expression. The devastating environmental pollution has burdened with numerous toxic chemicals of which biological compounds such as nucleic acid, proteins and membrane phospholipids were the potential targets leading to mutation, cell injury and death. The endogenous antioxidant systems falls prey in response to these toxic and deleterious oxidants and reactive oxygen species. In these conditions, exogenous chemopreventive compounds extracted from plant derived foods are required to maintain cell hemostasis. This review highlights the source and the chemopreventive mechanisms of genoprotective compounds from plant derived food.

Access this article online

Website:

http://nepjol.info/index.php/AJMS

DOI: 10.3126/ajms.v9i5.20177

E-ISSN: 2091-0576

P-ISSN: 2467-9100

Key words: Bioactivity; Chemoprevention; Genoprotection; Oxidative stress; Terrestrial plants

\section{INTRODUCTION}

Free radicals and their precursors are members of a reactive chemical family named reactive oxygen species such as $\mathrm{OH}, \mathrm{O} 2 \cdot-\mathrm{H}_{2} \mathrm{O}_{2},{ }^{1} \mathrm{O}_{2}$, ONOO. These reactive oxygen species are produced in normal cell metabolism. ${ }^{1}$ Human beings exploits the use of beneficial compounds derived from plant products as defense mechanisms or as signal inside or inter cells. So a useful level of beneficial reactive species is maintained inside cell by an equilibrium between the generating system producing free radicals such as mitochondrial respiration, phagocytosis, redox cycle or radiations, and the antioxidant systems such as scavenger molecules absorbed from the diet (vitamin C, E, carotenoids, polyphenols) or produced endogenously (glutathione, thioredoxin) or such as antioxidant enzymes (superoxide dismutases, glutathione peroxidases). ${ }^{2}$ When the production of pro-oxidant and their elimination by antioxidant systems were unbalanced, oxidative stress may unfortunately occur. ${ }^{3}$ Oxidative stress damages intracellular macromolecules, oxidizing lipids, DNA or proteins. ${ }^{1}$ Many cellular dysfunctions result from these biochemical damages, variable according to the level of stress: excess in cell proliferation, cell death by apoptosis, lipid deposition, and mutagenesis. ${ }^{4}$ By creating such disorders, oxidative stress is partly responsible for aging and age-related diseases as cancer, cardiovascular disorders, and neurodegenerative diseases as Alzheimer disease. ${ }^{1}$ DNA, one of the biological macromolecule is continuously degraded by endogenous oxidative stress leading to multiple types of DNA oxidative damages such as base oxidation, single or double strand breakage, mutation, DNA-protein cross links. ${ }^{5}$ 
To combat these biological macromolecules damage, cell has developed a number of antioxidant system to thwart the deleterious attacks of oxidative stress species. So, many antioxidant enzymes in cell living such as catalase, superoxide dismutase and glutathione peroxidases have the main function to regulate the production and the elimination of oxygen oxidative species and constitute the first line of cell antioxidant defense. ${ }^{6}$

In certain situations, endogenous antioxidant systems fails to nullify the toxic radicals and the exogenous antioxidant compounds are destined to take over the endogenous antioxidant system. Many therapeutical strategies have been tested in animal and human to prevent the occurrence of these oxidative diseases. ${ }^{6}$ They use nutritional improvement of antioxidant capacities, plant or chemical antioxidants. ${ }^{7}$ Chemists designed various new molecules chelating iron, scavenging free radicals or catalyzing destruction by miming the activity of antioxidant enzymes. But new ways of research have to be now explored to create more specific and gene targeted molecules able to protect/repair DNA damages but not only to destroy oxygen radicals. This review highlights the source and the chemopreventive mechanisms of genoprotective compounds from plant derived food.

\section{BIOACTIVE COMPONENTS OF PLANT FOOD AND THEIR BIOACTIVITY}

\section{Vitamins}

Ascorbic acid commonly found in oranges, Citrus, Tomatoes, is essential for cell living. The possible use of ascorbic acid in cancer therapy and prevention has been an area of great interest. Thus it is tempting to speculate that ascorbic acid supplements, if able to prevent the formation and/or promote the repair of pre-mutagenic oxidative DNA lesions, could be of use in cancer prevention. ${ }^{8}$ In addition, an early report showed that daily supplementation with ascorbic acid at high doses (grams) increased the survival time of terminal cancer patients and it was suggested that ascorbic acid could have important anticancer properties. Indeed, ascorbic acid kills or inhibits the growth of many tumor cell lines. There are also several reports showing that cancer cell lines are more sensitive to ascorbic acid than their non-malignant counterparts. ${ }^{10}$ It inhibits genotoxicity of dimethyl sulphate, ethyl methane sulfonate, methyl methane sulfonate and $\mathrm{N}$-nitroso $\mathrm{N}$-ethylurea in drosophila Ames test and repairs DNA damage induced by methyl methane sulfonate, cyclophosphamide, $\mathrm{FeSO}_{4}$ and $\mathrm{CuSO}_{4}$ in mouse blood cells in vivo. ${ }^{11,12}$ Ascorbic acid has exhibited antimutagenic effect on norfloxacin and diethylnitrosamine-induced mutagenicity in Salmonella typhimurium strains TA97, TA98 and TA100. ${ }^{4}$ It protected human skin from UV-irradiation and prevented DNA mutation by ROS scavenging. ${ }^{13}$

Vitamin E found in nuts, seeds and vegetable oils has glutathione regenerating properties and protect cell against oxidative stress injury. It inhibited norfloxacin and diethylnitrosamine induced mutagenicity in Salmonella typhimurium strains TA97, TA98 and TA100 and protected human skin from UV-irradiation. ${ }^{4,13}$ Vitamin $\mathrm{E}$ has also exhibited genoprotective effect on diazinon-induced DNA damage in rat in vivo. ${ }^{14}$

\section{Carotenoids}

Carotenoids such as $\beta$-carotene, lycopene, lutein, zeaxanthin as well as other carotenoids are found to be effective as anti-proliferative, anti-oxidant, learning and memory enhancer, sperm cryoconservation, biosurfactant as well as effective in brain neurodegenerative and Alzheimer disorders. ${ }^{15}$ Beta-carotene is a strongly colored red-orange pigment abundant in vegetables and fruits, especially in carrots and colorful vegetables. Beta-carotene is only synthesized in plants, not in humans or animals. In plants, beta-carotene absorbs light and energy is transferred to the chlorophyll for photosynthesis. Through consumption of fruits and vegetables rich in beta-carotene, one can lower the chances of cancer and heart disease. Also, study suggests that beta-carotene is helpful in people with the genetic condition erithropoietic protoporphyria. ${ }^{16}$ Intake of beta-carotene improves osteoarthritis, Alzheimer's disease, and cystic fibrosis. Additionally, beta-carotene helps protect the soft tissue and linings of the digestive tract, kidneys and bladder, and helps heal stomach ulcers. ${ }^{16}$ Betacarotene also protects the skin from aging, helps with the secretion of gastric juices necessary for proper digestion of proteins, helps building up strong teeth and bones and helps in the formation of visual purple, a substance that is in the eye necessary for proper night vision. ${ }^{16}$ Additionally, beta-carotene enhances wound healing, soothes mucus membranes, eases aching joints, eases pain of arthritis and protects against colon cancer. ${ }^{17}$ It protects human skin from UV-Irradiation and detoxifies hydrogen peroxide and L-arginine-induced DNA oxidative damage in human hepatocellular HepG2 Cells. ${ }^{13,16}$ Lycopene found in tomatoes, papaya, oranges protected lungs against squamous metaplasia and human skin from UV-Irradiation as well as from $\gamma$-radiation. ${ }^{13,18}$ It inhibits lipid peroxidation and possess antioxidant properties in primary culture of isolated rat hepatocytes in vitro. Additionally lycopene decreases the genotoxicity of N-methyl-N'-nitro-Nnitrosoguanidine. ${ }^{19}$ The xanthophyllic carotenoids such as lutein and zeaxanthin present in spinach, kale squash, peas, cabbage and mays orange have antioxidant properties and protects skin from lipid peroxidation induced by skin UV irradiation. ${ }^{20}$ Crocetin, the main bioactive compound of 
saffron scavenge free radicals, especially superoxide anions protects cells from oxidative stress. Crocetin is useful as sperm cryoconservation and in protecting hepatocytes from toxins. ${ }^{21}$ Because of its powerful antioxidant activity, it could be useful in the therapeutic intervention of neurodegenerative disorders. Recent developments on crocetin reveals that it do acts as a potent hepatoprotective agent, because of its protective property in vivo intoxication models in rats treated with aflatoxin B1 and dimethyl nitrosamine. ${ }^{21}$ The effect might be due to the hepatic tissues defense mechanism, which elevates the cytosol glutathione and the activities of glutathione S- transferase and glutathione peroxidase.Crocetin regulates cell cycle arrest by inhibiting DNA synthesis and RNA polymerase II activity in cancer cell. ${ }^{22}$

Terpenoids, omega-3 fatty acid and linoleic acid Terpenoids, also referred to as terpenes, are the largest group of natural compounds frequently found in citrus fruits, cherries and grapes. ${ }^{23}$ Most terpenes have biological activities and are used for the treatment of human diseases. ${ }^{23,24}$ Terpenoids are commonly classified as monoterpenes $\left(\mathrm{C}_{10}\right)$, sesquiterpenes $\left(\mathrm{C}_{15}\right)$, diterpenes $\left(\mathrm{C}_{20}\right)$, triterpenes $\left(\mathrm{C}_{30}\right)$. These terpenes display a wide range of biological activities against cancer, malaria, inflammation and a variety of infection diseases (viral and bacterial). ${ }^{25,26}$ The monoterpene d-limonene is an antitumor compounds by inducing apoptosis follow caspase-dependent mitochondrial death pathway in human leukemia cells. ${ }^{27}$ Its homologue geraniol mediated cell cycle arrest by p21Cip1 and p27Kip1 in human pancreatic adenocarcinoma cells and inhibited DNA topoisomerases. ${ }^{28}$ Studies reveals Menthol has anticancer activity by modulating the action of DNA topoisomerase I, II and promotes NF-î B expression in human gastric cancer SNU-5 cells. ${ }^{29}$ Dehydrocrotonin, a major diterperne in Croton cajucata inhibits methyl methane sulfonate, doxorubicin and mitomycin-induced micronuclei and apoptosis in CHO-K1 cell. ${ }^{30} \mathrm{Lupeol}$, a diterpene present in olive, mangoes, fig has modulating activity on NF-jB and PI3K/Akt pathways and inhibits skin cancer in CD-1 mice. ${ }^{31}$ Ursolic acid, a triterpene compound have shown to possess genoprotective effect on tert-butyl hydroperoxide ( $t$-BHP)-induced DNA damage in a human hepatoma cell line (HepG2). ${ }^{32}$ Castasterone contained in algae inhibited $\mathrm{H}_{2} \mathrm{O}_{2}$-induced DNA damage in human lymphocytes. ${ }^{33} \mathrm{Omega} 3$-fatty acid commonly found in algae and fish oils enhances NK cell-induced apoptosis of pancreatic cancer cells by linoleic acid down-regulation, phorbol ester-induced NF-kB activation and subsequent COX-2 expression in hairless mouse skin by targeting IkB kinase and PI3K-Akt. ${ }^{34}$

\section{Flavonoids and catechins}

Flavonoids are a group of polyphenolic compounds; which are widely spread throughout the plant kingdom. ${ }^{35}$ They are classified as flavones, flavanones, catechins and anthocyanins. Flavonoids possess pharmacological and biochemical effects, which inhibitsa number of enzymes such as aldose reductase, cyclooxygenase, xanthine oxidase, phosphodiesterase and lipoxygenase. ${ }^{36}$ They also have a regulatory role on different hormones like androgens, estrogens and thyroid. ${ }^{37}$ Recently, flavonoids were demonstrated to regulate signaling pathways by interaction with some regulator factors. ${ }^{38}$ Flavonoids possess genoprotective properties and can be used to fight against cancer development. ${ }^{35}$ Quercetin, Quercetin 3-O- $\alpha-\mathrm{L}$ rhamnoside, Myrecitin and Myrecitin 3-O- $\alpha-\mathrm{L}$ rhamnoside have exhibited anti-mutagenic activity in Salmonella strains TA98 (-S9,+S9) and TA97a (-S9). ${ }^{39}$ Quercitrin, Isoquercitrin and Rutin, possess antioxidant properties and inhibits chromosome damage in human lymphocytes exposed to hydrogen peroxide. ${ }^{40}$ Quercetin has also inhibited azoxymethane-induced colorectal carcinogenesis in F344 rats. ${ }^{41}$ Rutin exhibits some genoprotective effect against tert butyl hydroperoxide-induced DNA damages in human HepG2 cell and protects mouse bone marrow cell against X-Ray-irradiation. ${ }^{32,42}$ The tavonol kaempferol by its antioxidant properties protects human lymphocytes cells against the oxidative damages induced by hydrogen peroxide. ${ }^{43}$ The flavone tangeritin induced cell-cycle G1 arrest through inhibiting cyclin-dependent kinases 2 and 4 activities and through elevating Cdk inhibitors p21 and p27 in human colorectal carcinoma cells. ${ }^{44}$. Acacetin suppresses LPS-induced up-expression of iNOS and COX-2 in murine macrophages and TPA-induced tumor promotion in mice. ${ }^{45}$ Liteolin-7 glucoside has protective role against oxidation of DNA and stimulate DNA repair in cultured human cells. ${ }^{46}$ Apigenin exhibited genoprotective effect against hydrogen peroxide-induced genotoxic damage on cultured human peripheral blood lymphocytes and inhibited pancreatic cancer cell proliferation through G2/M cell cycle arrest. ${ }^{47,48}$ Its derivative 5 hydroxy $3,6,7,8,3^{\prime}, 4^{\prime}$ ' hexamethoxyflavone has anti-cancer properties and found to inhibit pancreatic cancer cell proliferation through G2/M cell cycle arrest, induced apoptosis through reactive oxygen species production, growth arrest and DNA damage-inducible gene 153 expression as well as caspase activation in human leukemia cells. ${ }^{48,49}$. It also exhibits inhibitory activity on 12-O-tetradecanoylphorbol 13-acetate-induced skin inflammation and tumor promotion in mice. ${ }^{50}$ Common flavanol such as peracetyl epicatechin gallate, catechin, epigallate catechin gallatte, epicatechin and acid chlorogenic were genoprotective compounds. So, peracetyl epicatechin gallate has prevented skin carcinogenesis by suppressing the PKD1-dependent signaling pathway in CD34+ skin stem cells and skin tumors. ${ }^{51}$ Catechin is an antioxidant and tumor cell growth modulators compound. ${ }^{52}$ Epicatechin and chlorogenic acid enhanced the intrinsic cellular 
tolerance against oxidative insults either by activating survival/proliferation pathways or by increasing antioxidant potential in HepG2 and so regulates cell apoptosis. ${ }^{53}$ Epigallatecatechingallatte inhibited colorectal aberrant crypt foci (ACF) formation and prevented oncogenic changes in dysplastic ACF in azoxymethane-treated F344 rats. $^{54}$ The flavanone naringenin protected $\mathrm{HaCaT}$ human keratinocytes against UVB-induced apoptosis and enhanced the removal of cyclobutane pyrimidine dimers from the genome..$^{55}$ The isoflavonoid genistein induced apoptosis of human breast cancer MCF-7 cells involves calpain-caspase and apoptosis signaling kinase 1-p38 mitogen-activated protein kinase activation cascades. ${ }^{56}$ Anthocyanins, major class of flavonoids has interesting biochemical activity due to their stability in food and their hydrogen donor ability. Delphinidin and cyanidin derived compounds such as delphinidin 3-glucoside, delphinidin 3 rutinoside, cyaniding, cyanidin 3-glucoside and cyanidin 3- rutinoside protected against DNA damage induced by tert-butyl-hydroperoxide in rat smooth muscle and hepatoma cells. ${ }^{57}$

\section{Proanthocyanidins and Flavanolignane}

Proanthocyanidins are synonymous with condensed tannins and are found in fruits, berries, beans, nuts, cocoa and wine. The abundance of proanthocyanidins in plants makes them an important part of the human diet. Proanthocyanidins inhibited mitogenic and survival-signaling in vitro and tumor growth in vivo. Proanthocyanidins also inhibited carrageenan-induced paw edema in rats and suppressed LPS-induced inflammation. ${ }^{6}$ Proanthocyanidin A2 treatment modulated antioxidant enzyme expression and decreased UVB-induced skin tumors. ${ }^{6}$ Silibinin protected against photocarcinogenesis via modulation of cell cycle regulators, mitogen-activated protein kinases and Akt signaling. ${ }^{58}$ Sylimarin protected human lymphocytes against L-arginine- induced genomic damages. ${ }^{16}$ Dibenzylbutyrolactone lignin (-)-hinokinin has exhibited an inhibitory effect on doxorubicin and methyl methane sulfonate clastogenicity in V79 chinese hamster lung fibroblasts. ${ }^{59}$ Secoisolariciresinol diglucoside protects non-malignant lung cells from radiation damage. ${ }^{60}$ Lignin isolated from oil palm black liquor waste defends mouse bone marrow against cyclophosphamide genotoxicity. ${ }^{61}$

\section{Other phenolic compounds}

Thymoquinone, the main essential oil of Nigella sativa $\mathrm{L}$. seeds has exhibited a genoprotective activity on doxorubicininduced damage in isolated human leukocytes. ${ }^{62}$ It has also inhibited phorbol ester-induced NF-jBactivation and COX-2 expression, and induced expression of cytoprotective enzymes in mouse skin in vivo. ${ }^{63}$ Boeravinone $\mathrm{G}$, a rotenoid compound isolated from Boerbaavia diffusa inhibited both TBARS and ROS formation induced by
Fenton's reagent, increased SOD activity and reduced $\mathrm{H}_{2} \mathrm{O}_{2}$-induced DNA damage. ${ }^{64}$ Additionally, boeravinone $\mathrm{G}$ decrease the levels of pERK1 and phospho-NF-kB p65 (but not of pERK2) under stress condition. ${ }^{64}$ Curcumin (diferuloylmethane), a bioactive ingredient of Curcuma longa, sowed potent anticancer properties in plethora human cancer cell lines/animal carcinogenesis model ${ }^{34}$ Curcumin modulated arsenic induced genotoxicity in human lymphocytes. ${ }^{65}$ However, It enhances NK cell-induced apoptosis in pancreatic cancer cells (Fiala, 2015) and inhibits interferon- $\gamma$ production. ${ }^{34,66}$ Additionally, curcumin reduces the hepatotoxicity induced by arsenic, cadmium, chromium, copper, lead and mercury, prevents histological injury, lipid peroxidation and glutathione (GSH) depletion, maintains the liver antioxidant enzyme status and protects against mitochondrial dysfunction. ${ }^{67}$ Trans $(\mathrm{t})$-resveratrol (3,4,5-trihydoxystilbene), present naturally in grapes and other fruits, induces Cdc2-tyr 15 phosphorylation via ATM/ ATR-Chk1/2-Cdc25C pathway considered as a central mechanism for $\mathrm{S}$ phase arrest in human ovarian carcinoma Ovcar-3 cells ${ }^{68}$ Its natural analogue pterostilbene, potently inhibited 7,12-dimethylbenz [a] anthracene (DMBA)/12O-tetradecanoylphorbol-13-acetate (TPA)-induced mouse skin carcinogenesis. ${ }^{69}$ Usnic acid is one of the most common and abundant metabolites found in variety of lichen genera, which are important source of biologically active compounds. It reduces frequencies of micronuclei and DNA damage induced by methyl methane sulfonate in V79 cells. ${ }^{23}$ Sinigrin, an abundant glucosinolate of B. carinata exhibited an antigenotoxic and anti-tumor activitiesin Drosophila melanogaster(SMART) in vivo and in HL60 (human promyelocytic leukaemia cell line) systems in vitro. ${ }^{70}$ Rosmarinic acid, the major phenolic compounds of Salvia sp protected Caco-2 and HeLa cells against genotoxicity of hydrogen peroxide and increased DNA repair activity in Caco-2 cells. ${ }^{71}$ Baccharin, the bioactive compounds isolated from the aerial parts of Baccharis dracunculifolia inhibits the genotoxic effects of methyl methane sulfonate and hydrogen peroxide in V79 cells. ${ }^{72}$ Carnosol, a regular constituent of Rosmarinus officinalis, is a phenolic diterpene. It inhibited the invasion of B16/F10 mouse melanoma cells by suppressing the metalloproteinase- 9 through down-regulating nuclear factor-kappaB and c-Jun. ${ }^{73}$ Carnosol and carnosic acid induced G2/M phase cell cycle arrest by inducing cyclin A and cyclin B1 levels alteration. ${ }^{74} 6$-gingerol, an abundant pungent elements of ginger inhibited cell adhesion, invasion, motility and activities of MMP-2 and MMP-9 in MDA-MB-231 human breast cancer cell lines. ${ }^{75}$-Shogaol (alkanone from Ginger) induced apoptotic cell death of human hepatoma p53 mutant mahlavusubline via an oxidative stress-mediated caspase-dependent mechanism. ${ }^{76}$ Oligonol, a formulation of catechin-type oligomers, showed inhibitory activity 
on phorbol ester-induced tumor promotion and COX-2 expression in mouse skin by targeting $\mathrm{NF}_{-j} \mathrm{~B}$ and $\mathrm{C} / \mathrm{EBP}$ pathways. ${ }^{63}$ Magnolol inhibits the transcriptional activation of $\mathrm{iNOS}$ and COX-2 mRNA in mouse skin that is stimulated by TPA. It inhibits the translocation of the nuclear factor$x \mathrm{~B}(\mathrm{NF} x \mathrm{~B})$ subunit and its binding to DNA by blocking the phosphorylation of $\mathrm{I} x \mathrm{BR}$ and p 65 resulting in the subsequent degradation of I $x$ BR. ${ }^{77}$ Additionally, magnolol can suppress TPA-induced activation of extracellular signal-regulated kinase (ERK)1/2, p38 mitogen-activated protein kinase (MAPK), and phosphatidylinositol 3-kinase $(\mathrm{PI} 3 \mathrm{~K}) / \mathrm{Akt}$ that are involved in tumor migration and invasion. ${ }^{77}$ Magnolol inhibited the 7, 12-dimethylbene[a] anthracene(DMBA)/TPA-induced skin tumor formation by reducing the tumor multiplicity, tumor incidence and tumor size of papillomas. ${ }^{77}$

\section{REFERENCES}

1. Aggarwal BB and Shishodia S. Molecular targets of dietary agents for prevention and therapy of cancer. Biochem Pharmacol 2006;71(10): 1397-1421.

2. Dani C, Pasquali MB, Oliveira MR, Umezu FM, Salvador M, Henriques JP, et al. Protective effects of purple grape juice on carbon tetrachloride-induced oxidative stress in brains of adult Wistar rats.J Med Food2008;11(1): 55-61.

3. Kumar R, Das M and Ansari KM, Nexrutine inhibits tumorigenesis in mouse skin and induces apoptotic cell death in human squamous carcinoma A431 and human melanoma A375 cells. Carcinogenesis 2012;33(10): 1909-1918.

4. González-Avila M, Arriaga-Alba M, Garza M, Hernández $M$, Domínguez-Ortíz M, Fattel-Fazenda $S$, et al. Antigenotoxic, antimutagenic and ROS scavenging activities of a Rhoeo discolor ethanolic crude extract. Toxicol in Vitro 2003;17(1): 77-83.

5. Dinkova-Kostova AT, Jenkins SN, Fahey JW, Ye L, Wehage SL, Liby $\mathrm{KT}$, et al. Protection against UV-light-induced skin carcinogenesis in SKH-1 high-risk mice by sulforaphanecontaining broccoli sprout extracts. Cancer Letters 2006;240(2): 243-252.

6. Pan $\mathrm{MH}$ and Ho CT. Chemopreventive effects of natural dietary compounds on cancer development. Chem Society Rev 2008;37(11): 2558-2574.

7. Ramos S. Cancer chemoprevention and chemotherapy: Dietary polyphenols and signalling pathways. Molecular Nutrition Food Res 2008;52(5): 507-526.

8. Hacişevki A. An overview of ascorbic acid biochemistry. Ankara Universitesi Eczacilik Fakultesi Dergisi 2009;38(3): 233-255.

9. Lutsenko EA, Cárcamo J and Golde DW. Vitamin C prevents DNA mutation induced by oxidative stress. J Biol Chem 2002;212: 1-28.

10. Kaya B. Anti-Genotoxic Effect of Ascorbic Acid on Mutagenic Dose of Three Alkylating Agents. Turk J Biol 2003;27: 241-246.

11. Franke SI, Prá D, Da Silva J, Erdtmann B and Henriques JA. Possible repair action of Vitamin C on DNA damage induced by methyl methanesulfonate, cyclophosphamide, $\mathrm{FeSO} 4$ and CuSO4 in mouse blood cells in vivo. Mutation Res. - Genetic Toxicol Environmental Mutagenesis2005;583(1): 75-84.

12. Prava MB, Ranjan MM and Kanti TN. Antimutagenic Effects of Ascorbic Acid against the Genotoxicity of Dimethyl Sulphate in Drosophila. Universal J Res Environmental Res Technol 2002;2(1): 77-84.

13. Greul AK, Grundmann JU, Heinrich F, Pfitzner I, Bernhardt J, Ambach A, et al. Photoprotection of UV-irradiated human skin: An antioxidative combination of vitamins $\mathrm{E}$ and $\mathrm{C}$, carotenoids, selenium and proanthocyanidins. Skin Pharma. Applied Skin Physiol 2002;15(5): 307-315.

14. Yassa VF, Girgis SM and Abumourad IM. Potential protective effects of vitamin $E$ on diazinon-induced DNA damage and some haematological and biochemical alterations in rats. J Mediterranean Ecology 2011;11: 31-39.

15. Woods J, Bilton RF and Young AJ. $\beta$-Carotene enhances hydrogen peroxide-induced DNA damage in human hepatocellular HepG2 cells. FEBS Letters 1999;449(2-3): 255-258.

16. Yurtcu E, Kasapoğlu E and Sahin IF. Protective effects of $\beta$-carotene and silymarin on human lymphocytes. Turkish $\mathrm{J}$ Biol 2012;36(1): 47-52.

17. Russell RM. Functions and actions of retinoids and carotenoids : building on the vision of james allen olson. American Society Nutr Sci 2004;262-268.

18. Srinivasan M, Sudheer R, Pillai KR, Kumar PR, Sudhakaran PR and Menon VP. Lycopene as a natural protector against gamma-radiation induced DNA damage, lipid peroxidation and antioxidant status in primary culture of isolated rat hepatocytes in vitro. Biochimica Biophysica Acta 2007;1770(4): 659-665.

19. Velmurugan B, Santhiya ST and Nagini S. Protective effect of $\mathrm{S}$-allycysteine and lycopene in combinaison against $\mathrm{N}$-methylN'nitro-N-nitrosoguanidine-induced genotoxicity. Polish J Pharm 2004;56: 241-245.

20. Palombo P, Fabrizi G, Ruocco V, Ruocco VE, Fluhr J, Roberts R, et al. Beneficial long-term effects of combined oral/topical antioxidant treatment with the carotenoids lutein and zeaxanthin on human skin: A double-blind, placebo-controlled study. Skin Pharmacol. Physiology 2007;20(4): 199-210.

21. Singla RK and Bhat GV. Crocin : An Overview. Indo Global J Pharma Sc 2011;1(4): 281-286.

22. Gutheil WG, Reed G, Ray A and Dhar A. Crocetin: an agent derived from from saffron for prevention and therapy for cancer. Curr Pharm Biotechnol 2015;13(1): 173-179.

23. Leandro LM,Vargas FS, Barbosa PC, Neves JK, Silva JA and Veiga-Junior VF. Chemistry and biological activities of terpenoids from copaiba (Copaifera spp.) oleoresins. Molecules 2012;17(4), 3866-3889.

24. Leandro LF, Munari CC, Sato VL, Alves JM, Oliveira PF, Mastrocola DF, et al. Assessment of the genotoxicity and antigenotoxicity of (+)-usnic acid in V79 cells and Swiss mice by the micronucleus and comet assays. Mutation Res Genetic Toxicol Environmental Mutagenesis 2013;753(2): 101-106.

25. Zeyad DN, Aisha A and Abdul Majid A. The pharmacological properties of terpenoids from Sandoricum koetjape. WebmedCentral 2010;1(12): 1-11.

26. Khan MT, Ather A, Pinto AC and Maciel MM. Potential benefits of the 19-nor-clerodane trans-dehydrocrotonin on the central nervous system. Brazilian J Pharma 2009;19(1): 7-13.

27. Wang L, Gao S, Jiang W, Luo C, Xu M, Bohlin L, et al. Antioxidative dietary compounds modulate gene expression associated with apoptosis, DNA repair, inhibition of cell proliferation and migration. Int J Mol Sci 2014;15(9): 16226-16245.

28. Ji J, Zhang L, Wu Y, Zhu X and Sun XZ. Induction of apoptosis by d-limonene is mediated by a caspase-dependent mitochondrial death pathway in human leukemia cells. Leukemia Lymphoma 2006;47(12): 2617-2624.

29. Wiseman DA, Werner SR and Crowell PL. Cell cycle arrest by the isoprenoids perillyl alcohol, geraniol and farnesol is mediated 
by $\mathrm{p} 21 \mathrm{Cip} 1$ and $\mathrm{p} 27 \mathrm{Kip} 1$ in human pancreatic adenocarcinoma cells. J Pharm Exp Ther 2007;320(3): 1163-1170.

30. Lin J, Lu H, Lee J, Lin J, Hsia TC, Wu LT, et al. (-) -Menthol inhibits DNA topoisomerases I, II and B , and promotes NF- îB expression in human gastric cancer SNU- 5 cells. Anticancer Res 2005;25: 2069-2074.

31. PoerschA, Vieira F, Aparecida M, Maciel M, Camara PK, NeumaT, et al. Protective effect of DCTN (trans -dehydrocrotonin) against induction of micronuclei and apoptosis by different mutagenic agents in vitro. Mutation Res 2007;629: 14-23.

32. Saleem M, Afaq F, Adhami VM and Mukhtar H. Lupeol modulates NF-kappaB and PI3K/Akt pathways and inhibits skin cancer in CD-1 mice. Oncogene 2004;23: 5203-5214.

33. Ramos AA, Lima CF, Pereira ML, Fernandes-Ferreira M and Pereira-Wilson C. Antigenotoxic effects of quercetin, rutin and ursolic acid on HepG2 cells: Evaluation by the comet assay. Toxicol Letters 2007;10:1-25.

34. Sondhi N. Inhibition of $\mathrm{H} 2 \mathrm{O} 2$-induced DNA damage in single cell gel electrophoresis assay (comet assay) by castasterone isolated from leaves of centella asiatica. Health 2010;2(6): 595-602.

35. Fiala M. Curcumin and omega-3 fatty acids enhance NK cellinduced apoptosis of pancreatic cancer cells but curcumin Inhibits Interferon- $y$ production: Benefits of omega-3 with curcumin against cancer. Molecules 2015;20(2): 3020-3026.

36. Saxena M, Saxena J and Pradhan A. Flavonoids and phenolic acid as antioxidants in plants and human health. Int J Pharm Sci Rev Res 2012;16(2): 130-134.

37. Chae SC, Lee JH and Park SU. Recent studies on flavonoids and their antioxidant activities. EXCLI Journal 2013;12: 226-230.

38. Narayana KR., Reddy MR, Chaluvadi MR and Krishna DR. Bioflavonoids Classification, Pharmacological, Biochemical Effects and Therapeutic Potential. Indian J Pharmacol 2001;33: 2-16.

39. Biso $\mathrm{Fl}$, Rodrigues $\mathrm{CM}$, Rinaldo $\mathrm{D}$, Reis MB, Bernardi CC, Mattos JC, et al. Assessment of DNA damage induced by extracts, fractions and isolated compounds of Davilla nitida and Davilla elliptica (Dilleniaceae). Mutation ResGenetic Toxicol Environmental Mutagenesis 2010;702(1): 92-99.

40. Boligon AA, Sagrillo MR, Machado LF, Filho OD, Machado MM, Cruz MI,et al. Protective effects of extracts and flavonoids isolated from scutia buxifolia reissek against chromosome damage in human lymphocytes exposed to hydrogen peroxide. Molecules 2012;17(5): 5757-5769.

41. Dihal A, Boer VC, Van der Woude H, Tilburgs C, Bruijntjes JP, Alink GM,et al. Quercetin, but not its glycosidated conjugate rutin, inhibits azoxymethane-induced colorectal carcinogenesis in F344 rats. J Nutrition 2006;136: 2862-2867.

42. Benavente-Garcia $\mathrm{O}$, Castillo J, Lorente $\mathrm{J}$ and Alcaraz $\mathrm{M}$. Radioprotective effects in vivo of phenolics extracted from Olea europaeleaves against X-ray-induced chromosomal damage: comparative study versus several flavonoids and sulfurcontaining compounds. J Med Food 2002;5(3): 125-135.

43. Gafrikova M, Galova E, Sevcovicova A, Imreova P, Mucaji P and Miadokova E. Extract from armoracia rusticana and its flavonoid components protect human lymphocytes against oxidative damage induced by hydrogen peroxide. Molecules 2014;19(3): 3160-3172.

44. Pan MH, Chen WJ, Lin-Shiau SY, Ho CT and Lin JK. Tangeretin induces cell-cycle $\mathrm{G} 1$ arrest through inhibiting cyclin-dependent kinases 2 and 4 activities as well as elevating Cdk inhibitors p21 and p27 in human colorectal carcinoma cells. Carcinogenesis 2002;23(10), 1677-1684.

45. Pan M, Lai C, Wang $Y$ and Ho C. Acacetin suppressed LPS-induced up-expression of iNOS and COX-2 in murine macrophages and TPA-induced tumor promotion in mice. Biochem. Pharmacol 2006;72: 1293-1303.

46. Ramos A, Azqueta A, Pereira-Wilson C and Collins AR. Polyphenolic compounds from salvia species protect cellular DNA from oxidation and stimulate DNA repair in cultured human cells. J Agricultural Food Chemistry 2010;58(12): 7465-7471.

47. Siddique $\mathrm{YH}$ and Afzal M. Protective effect of apigenin against hydrogen peroxide induced genotoxic damage on cultured human peripheral blood Iymphocytes. J Applied Biomed 2009;7(1214): 35-43.

48. Ujiki MB, Ding XZ, Salabat MR, Bentrem DJ, Golkar L, Milam B, et al. Apigenin inhibits pancreatic cancer cell proliferation through G2/M cell cycle arrest. Molecular Cancer 2006;5(76): 1-8.

49. Pan MH, Lai YS, Lai CS, Wang YJ, Li S, Lo CY, et al. 5-hydroxyl-3,6,7,8, 3', 4'-hexamethoxyflavone induces apoptosis through reactive oxygen species production, growth arrest and DNA damage-inducible gene 153 expression, and caspase activation in human leukemia cells. J Agric Food Chem 2007;55:5081-5091.

50. Lai C, Li S, Chai C, Dushenkov S, Ho C and Wang Y. Antiinflammatory and antitumor promotional effects of a novel urinary metabolite, 3',4' -didemethylnobiletin, derived from nobiletin. Carcinogenesis 2008;29(12): 2415-2424.

51. Chiou YS, Sang S, Cheng KH, Ho CT, Wang YJ and Pan MH. Peracetylated (-)-epigallocatechin-3-gallate (AcEGCG) potently prevents skin carcinogenesis by suppressing the PKD1dependent signaling pathway in CD34+ skin stem cells and skin tumors. Carcinogenesis 2013;34(6): 1315-1322.

52. Faria $A$, Calhau $C$, De Freitas $V$ and Mateus N. Procyanidins as antioxidants and tumor cell growth modulators. J Agri Food Chem 2006;54(6): 2392-2397.

53. Granado-Serrano AB, Martin MA, Izquierdo-Pulido M, Goya L, Bravo L and Ramos S. Molecular Mechanisms of (-) -epicatechin and chlorogenic acid on the regulation of the apoptotic and survival/proliferation pathways in a human hepatoma cell line. J Agri Food Chem 2007;55: 2020-2027.

54. Xiao H, Hao X, Simi B, Ju J, Jiang H, Reddy BS, et al. Green tea polyphenols inhibit colorectal aberrant crypt foci (ACF) formation and prevent oncogenic changes in dysplastic ACF in azoxymethane-treated F344 rats. Carcinogenesis 2008;29(1): 113-119.

55. El-Mahdy M, Zhu Q, Wang QE, Wani G, Patnaik S, Zhao Q, et al. Naringenin protects $\mathrm{HaCaT}$ human keratinocytes against UVBinduced apoptosis and enhances the removal of cyclobutane pyrimidine dimers from the genome. Photochemistry Photobiology 2008;84(2): 307-316.

56. Shim H, Park J, Paik H, Nah S, Kim DS and Han SY. Genisteininduced apoptosis of human breast cancer MCF-7 cells involves calpain - caspase and apoptosis signaling kinase 1 - p38 mitogen-activated protein kinase activation cascades. AntiCancer Drugs 2007;18(6): 649-657.

57. Lazzé MC, Pizzala R, Savio M, Stivala L, Prosperi E and Bianchi L. Anthocyanins protect against DNA damage induced by tert-butyl-hydroperoxide in rat smooth muscle and hepatoma cells. Mutation Res.Genetic Toxicol. Environmental Mutagenesis 2003;535(1): 103-115.

58. Mallikarjuna G, Dhanalakshmi S, Singh RP, Agarwal C and Agarwal R. Silibinin protects against photocarcinogenesis via modulation of cell cycle regulators, mitogen-activated protein kinases and Akt signaling. Cancer Res 2004;64(1): 6349-6356.

59. Resende FA, Tomazella IM, Barbosa LC, Ponce M, Furtado A, Pereira AC, et al. Effect of the dibenzylbutyrolactone lignan (-)-hinokinin on doxorubicin and methyl methanesulfonate clastogenicity in V79 Chinese hamster lung fibroblasts. Mutation 
Res.Genetic Toxicol. Environmental Mutagenesis 2010;700(1-2): 62-66.

60. Velalopoulou A, Tyagi S, Pietrofesa R, Arguiri E and Christofidou-Solomidou M. The flaxseed-derived lignan phenolic secoisolariciresinol diglucoside (SDG) protects non-malignant lung cells from radiation damage. Int J Mol Sci 2015;17(1): 1-15.

61. Naik P, Rozman HD and Bhat R. Genoprotective effects of lignin isolated from oil palm black liquor waste. Environmental Toxicol Pharmacol 2013;36(1): 135-141.

62. Al-Shdefat RI, Abd-Elaziz M and Al-Saikhan FI. Genoprotective and genotoxic effects of thymoquinone on doxorubicin-induced damage in isolated human leukocytes. Tropical JPharma Res 2014;13(12): 2015-2020.

63. Kundu K, Liu M, Shin J and Surh Y. Thymoquinone inhibits phorbol ester-induced activation of NF- KB and expression of COX-2, and induces expression of cytoprotective enzymes in mouse skin in vivo. Biochem.Biophys. Res Communications 2013;2013: 3-7.

64. Aviello G, Canadanovic-Brunet JM, Milic N, Capasso R, Fattorusso E, Taglialatela-Scafati $\mathrm{O}$,et al. Potent antioxidant and genoprotective effects of boeravinone $\mathrm{G}$, a rotenoid isolated from Boerhaavia diffusa. PLoS ONE 2011.6(5): 1-11.

65. Sinha D, Mukherjee S, Roy S, Bhattacharya RK and Roy M. Modulation of arsenic induced genotoxicity by curcumin in human lymphocytes. J Environmental Chem Ecotoxicol 2009;1(1): 001-011.

66. Tawfik SS, Abouelella AM and Shahein YE. Curcumin protection activities against $Y$-Rays-induced molecular and biochemical lesions. BMC Res Notes 2013;6(1): 1-10.

67. Garcia-Nino WR and Pedraza-Chaverri J. Protective effect of curcumin against heavy metals-induced liver damage. Food Chem Toxicol 2014;69: 182-201.

68. Tyagi A, Singh RP, Agarwal C, Siriwardana S, Sclafani R and Agarwal R. Resveratrol causes Cdc2-tyr15 phosphorylation via ATM/ATR-Chk1/2-Cdc25C pathway as a central mechanism for $\mathrm{S}$ phase arrest in human ovarian carcinoma Ovcar-3 cells. Carcinogenesis 2005;26(11): 1978-1987.
69. Tsai ML, Lai CS, Chang YH, Chen WJ, Hoc CT and Pan MH. Pterostilbene, a natural analogue of resveratrol, potently inhibits 7,12-dimethylbenz[a]anthracene (DMBA)/12-Otetradecanoylphorbol-13-acetate (TPA)-induced mouse skin carcinogenesis. Food Function 2012;3:1185-1194.

70. Lozano-Baena MD, Tasset I, Obregón-Cano S, Haro-Bailon A, Muñoz-Serrano A and Alonso-Moraga A. Antigenotoxicity and tumor growing inhibition by leafy Brassica carinata and sinigrin. Molecules 2015;20(9): 15748-15765.

71. Oliveira PF, Leandro LF, Montanheiro G, Bastos JK, Filho AA and Tavares DC. Baccharin Prevents Genotoxic Effects Induced by Methyl Methanesulfonate and Hydrogen Peroxide in V79 Cells. J Food Sci 2012;77(8): 1-10.

72. Huang SC, Ho CT, Lin-Shiau SY and Lin JK. Carnosol inhibits the invasion of B16/F10 mouse melanoma cells by suppressing metalloproteinase-9 through down-regulating nuclear factorkappaB and c-Jun. Biochem Pharmacol 2005;69(2): 221-232.

73. Visanji JM, Thompson DG and Padfield PJ. Induction of G2/M phase cell cycle arrest by carnosol and carnosic acid is associated with alteration of cyclin A and cyclin B1 levels. Cancer Letters 2006;237(1): 130-136.

74. Lee HS, Seo EY, Kang NF and Kim WK. [6]-Gingerol inhibits metastasis of MDA-MB-231 human breast cancer cells. J Nutr Biochem 2008;19(5), 313-319.

75. Chen CY., Liu TZ, Liu YW, Tseng WC, Liu RH, Lu FJ,et al. 6-Shogaol (Alkanone from Ginger) induces apoptotic cell death of human hepatoma p53 mutant mahlavu subline via an oxidative stress-mediated caspase-dependent mechanism. J AgriFood Chemistry 2007;55(3): 948-954.

76. Kundu KJ, Hwang D, Lee J, Chang E, Shin KY, Fujii H, et al. Inhibitory effects of oligonol on phorbol ester-induced tumor promotion and COX-2 expression in mouse skin : NF- KB and C/EBP as potential targets. Cancer Letters 2009;273(1): 86-97.

77. Kuo DH, Lai Y, Lo CY, Cheng AC, Wu H and Pan MH. Inhibitory effect of magnolol on TPA-induced skin inflammation and tumor promotion in mice. J Agri Food Chem 2010;58: 5777-5783.

\footnotetext{
Authors Contribution:

AR-Reviewed the literature, Manuscript preparation; MC- Reviewed the literature, helped in preparing first draft of manuscript, checked and corrected the grammar; MK-Corrected and validated the final report.

Work Attributed to: Laboratory of Applied Biochemistry and Chemistry, UFR-SVT, University Ouaga 1 Pr Joseph KI-ZERBO (Burkina Faso).

Orcid ID:

Dr. Ablassé Rouamba - (1) https://orcid.org/0000-0003-3498-483X

Dr. Moussa Compaoré - (D) https://orcid.org/0000-0003-1916-5457

Pr Martin Kiendrebeogo - (i) https://orcid.org/0000-0001-6910-6370

Source of Support: International Foundation of Science (IFS), Stockholm supported the literature and documentation charges under the IFS Grants F/5539-1, Conflict of Interest: None declared.
} 